\title{
Factors Predicting Whom to Screen for Coeliac Disease in Patients with Diarrhoea Predominant Irritable Bowel Syndrome in Developing Countries
}

\author{
Vaibhav Somani*, Apurva Shah and Deepak Amarapurkar \\ Department of Gastroenterology, Bombay Hospital \& Research Center, Mumbai, India
}

Received: 05 April, 2016; Accepted: 10 May, 2016; Published: 11 May, 2016

*Corresponding author: Vaibhav Somani, Department of Gastroenterology and Hepatology, 2nd floor, Endoscopy Department, MRC wing, Bombay Hospital and Medical Research Center, 12 - New Marine Lines,Mumbai-400020, India, Telephone: 022-22067676;Ext: 367; Emailvaibhav_doctor@yahoo.com

\begin{abstract}
AIM: Screen all patients with irritable bowel syndromediarrhoea (IBS-D) for coeliac disease (CD) is no cost effective strategy in developing countries. So we planned this study to look for the clinical features and laboratory parameters useful to screen the patients of IBS-D for CD.

Methods: We prospectively analyzed this retrospectively maintained data of 198 patients with chronic diarrhoea. IgA anti endomysial antibodies (EMA) and IgA were done in all patients and oesophagogastroduodenoscopy was done in patients with positive EMA (>40units $/ \mathrm{ml}$ ) and wherever indicated. Based on results of EMA, duodenal biopsy with or without HLADQ2or 8, we divided patients in to two groups (CD group and IBS-D group).We then analyzed clinical features and laboratory parameters by univariate and multivariate analysis, to look for the features more suggestive of CD.
\end{abstract}

Results: Of 198 patients, 98 were diagnosed to have CD and of remaining 100 patients 78 patients had IBS-D. Multivariate analysis revealed duration of symptoms more than 6 months , iron deficiency anaemia(IDA), hemoglobin(Hb) less than $10 \mathrm{gm} / \mathrm{dl}$, presence of bone pains and transaminasemia (alanine aminotransferase more than $40 \mathrm{mu} / \mathrm{ml}$ ) to be statistically significant and suggestive of CD.

Conclusion: Patient with chronic diarrhoea, who has any one or more of the following features like duration of symptoms more than 6 months, IDA, Hb less than $10 \mathrm{gm} / \mathrm{dl}$, bone pains and transaminasemia, should be screened for $\mathrm{CD}$.

Keywords: Chronic Diarrhoea; Coeliac Disease; Irritable Bowel Syndrome; Anti Endomysial Antibody

\section{Introduction}

Differential diagnosis of chronic diarrhoea and whom to screen for coeliac disease (CD) among diarrhoea predominant irritable bowel syndrome (IBS-D) is an important dilemma amongst the gastroenterologist. Major differential diagnosis of chronic diarrhoea includes common conditions like IBS-D, tropical sprue, small intestinal bacterial overgrowth syndrome (SIBO) and coeliac disease. Prevalence estimates for IBS varies from $1-45 \%$ worldwide, data from a meta analysis of community based studies suggest that $22 \%$ of sufferers have IBSConstipation, 23\% IBS-D, 24\% IBS-Mixed and remainder were IBS-Undetermined [1].Individuals with IBS-D report abdominal pain, bloating, and diarrhoea, symptoms similar to those in CD. IBS-D is a diagnosis of exclusion and current professional society guidelines recommend performing a limited battery of tests to exclude common organic diseases masquerading as IBS [2]. Studies suggest that the prevalence of CD is increased in individuals with IBS; however, evidence is conflicting, and current guidelines do not always recommend screening for CD in these individuals. Prevalence of biopsy-proved CD in cases meeting diagnostic criteria for IBS was more than 4-fold that in controls without IBS [3].

With data showing that patients with IBS-D may benefit from gluten free diet (GFD), GFD is used with increasing frequency in IBS-D patients [4-6]. Although there is little harm beyond cost to a patient on a balanced GFD,CD may be overlooked and complications ignored. So should panels of serologic studies for CD be more widely used in IBS-D patients? The widespread use of panels would not be cost-effective as first-line testing; although it may slightly improve overall sensitivity, it reduces specificity, leading to unnecessary endoscopy [7].

We planned this study to look for the clinical features and laboratory parameters which can determine who should be screened for CD and referred for small bowel biopsy in patients presenting with diarrhoea and help to differentiate between CD and non CD aetiology like IBS-D.

\section{Materials and Methods}

We retrospectively analyzed prospectively maintained data of 198 consecutive patients attending the Gastroenterology clinic at our institute over a period of 2008 to 2015 with chronic diarrhoea. All patients were evaluated by history, physical examination and blood investigations which included complete blood count, liver function tests, serum creatinine, serum albumin, serum iron studies, serum B12 level and serum calcium levels. IgA anti endomysial antibodies (EMA) were done in all 
patients and oesophagogastroduodenoscopy was done in all those patients with positive EMA and whenever indicated. IgA deficiency was ruled out. Based on results of EMA and duodenal biopsy we divided patients in to two groups first is CD group (diagnosed by modified ESPGHAN criteria- anti EMA, marsh staging of duodenal biopsy and HLA DQ2 and DQ8 if needed) and second IBS-D group(as shown in flow chart). Diagnosis of IBS-D was done according to Rome III criteria [8].We then compared clinical features and laboratory parameters of patients with $C D$ and IBS-D by univariate and multivariate analysis.

\section{Statistical Analysis}

Data were analyzed using SPSS V 21.0 (Statistical Package for Social Sciences Version 21.0) package. Descriptive statistics were given as mean \pm standard deviation and qualitative data were given as number (Percentage \%). Student's unpaired T test was applied to compare mean of quantitative variables between CD and IBS-D. Chi square test with Continuity correction or Fisher Exact Probability test was used to compare percentages of qualitative variables. Binary logistic regression model was applied to predict group (CD or IBS-D) with the help of predictor variables like age more than or less than 40 year, sex (male or female), body mass index(BMI) more than or less than $18.5 \mathrm{~kg} /$ $\mathrm{m}^{2}$, weight loss of more than $10 \%$ in 6 months, mean duration of symptoms (more than or less than 6months), Iron Deficiency anaemia (IDA)present or absent, mean hemoglobin( $\mathrm{Hb}$ ) level more or less than $10 \mathrm{gm} / \mathrm{dl}$, mean platelet count more than or less than 4.5 lakh/cumm, mean serum B12 levels more than or less than $200 \mathrm{pg} / \mathrm{ml}$, mean serum albumin more than or less than $3 \mathrm{gm} \%$, bone pains present or absent, mean serum calcium more than or less than $8 \mathrm{mg} \%$ and alanine aminotransferase (ALT) more than or less than $40 \mathrm{mu} / \mathrm{ml}$ [9-14].All statistical tests were two tailed. Level of Significance was taken as $\mathrm{P}<0.05$.

\section{Results}

Out of the 198 consecutive patients with watery diarrhoea, 98 were diagnosed to have $\mathrm{CD}$ and out of remaining100 patients 78, 12 and 10 patients had diarrhoea predominant IBS, tropical sprue and SIBO respectively. Clinical and laboratory parameters of patients of two groups CD and IBS-D were compared. The results in patients with $\mathrm{CD}$ group showed mean age(years) of $33.54 \pm 15.73, \mathrm{BMI}\left(\mathrm{kg} / \mathrm{m}^{2}\right)$ of $21.74 \pm 4.44, \mathrm{Hb}$ levels $(\mathrm{gm} / \mathrm{dl})$ $10.14 \pm 2.34$, platelet count (lakh/cumm) of $3.39 \pm 1.43$, serum calcium(mg\%) of $8.78 \pm 0.76$, Serum albumin (gm\%) $3.83 \pm 0.62$, serum B12 levels of $489.89 \mathrm{pg} / \mathrm{ml}$ (median value) and ALT 48.74 $\mathrm{mu} / \mathrm{ml}$ (median value). On univariate analysis of the clinical and laboratory parameters of both groups, statistically significant difference was found amongst 5 variables - significant weight loss , presence of IDA , Hb less than $10 \mathrm{gm} / \mathrm{dl}$, serum calcium less than $8 \mathrm{mg} \%$ and serum albumin less than $3 \mathrm{gm} \%$. Presence of any of these parameters was in favour of diagnosis of coeliac disease (as shown in table 1). On multivariate analysis the fit of model was good with percent accuracy of $71.2 \%$. The model revealed that out of all above predictor variables duration of symptoms more than 6 months, IDA, Hb less than $10 \mathrm{gm} / \mathrm{dl}$, presence of bone pains and transaminesemia (ALT more than $40 \mathrm{mu} / \mathrm{ml}$ ) turned out to be statistically significant.

\section{Discussion}

It is not practical and cost effective to screen all the patients with chronic diarrhoea especially IBS-D for CD [15]. Primary care physicians should be able to decide whom to refer to gastroenterologist for further work up. This study points out some of the important parameters presence of which can help to suspect presence of CD. This knowledge may increase the detection of $\mathrm{CD}$.

In many Asian nations, $\mathrm{CD}$ is still considered to be either non-existent or very rare, which is not true. In adults, the classic gastrointestinal manifestations include diarrhoea, steatorrhea, excessive flatulence and abdominal distension, weight loss, malaise, and recurrent aphthous ulcers [16, 17]. However, gastrointestinal symptoms can also mimic those of IBS-D [1820]. There is emerging evidence to suggest that the prevalence of $\mathrm{CD}$ is higher among patients with IBS than in controls [2].Pooled odds ratios (95\% confidence intervals) for positive endomysial antibodies and biopsy-proved coeliac disease in cases meeting diagnostic criteria for IBS compared with controls without IBS

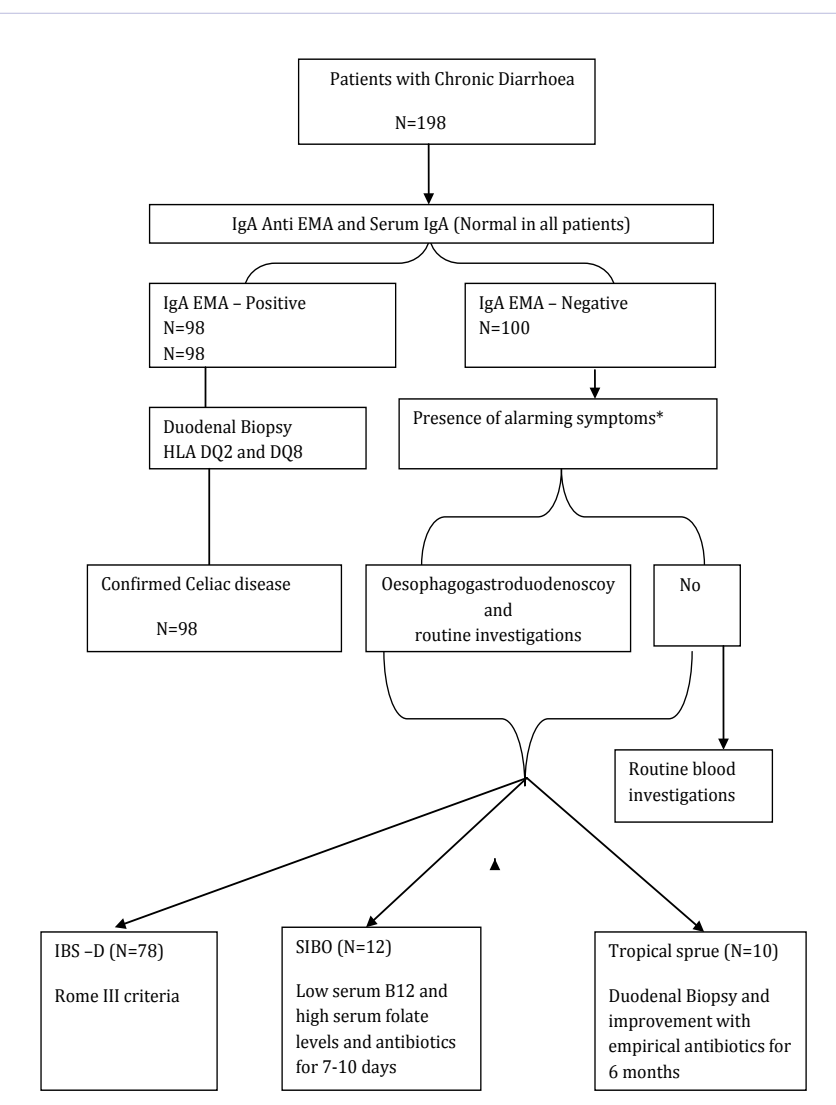

Figure 1: *Alarming symptoms included any history of bleeding or unexplained weight loss, evidence of anaemia, unexplained vomiting, progressive dysphagia, a family history of malignancy, and new onset symptoms in older age. 
Table 1: Comparison of Demography, clinical features and laboratory parameters among patients with CD and IBS-D.

\begin{tabular}{|c|c|c|c|c|}
\hline Variables & Category & $\begin{array}{l}\text { IBS-D } \\
(\mathrm{n}=78)\end{array}$ & $\begin{array}{l}\text { Coeliac disease } \\
(n=98)\end{array}$ & $P$ value \\
\hline \multirow{2}{*}{ Age (years) } & $\leq 40$ & $50(64.0 \%)$ & $60(61.2 \%)$ & \multirow{2}{*}{$\mathrm{P}=0.40$} \\
\hline & $>40$ & $28(36.0 \%)$ & $38(38.8 \%)$ & \\
\hline \multirow{2}{*}{ Sex } & Female & $42(54.0 \%)$ & $64(65.3 \%)$ & \multirow{2}{*}{$P=0.1$} \\
\hline & Male & $36(46.0 \%)$ & $34(34.7 \%)$ & \\
\hline \multirow{2}{*}{ BMI $\left(\mathrm{kg} / \mathrm{m}^{2}\right)$} & $\leq 18.5$ & $18(23.0 \%)$ & $23(23.5 \%)$ & \multirow{2}{*}{$\mathrm{P}=1.0$} \\
\hline & $>18.5$ & $60(77.0 \%)$ & $75(76.5 \%)$ & \\
\hline \multirow{2}{*}{$\begin{array}{l}\text { Weight loss } \\
\text { (10\% or more in } 6 \text { months ) }\end{array}$} & Yes & $25(32.0 \%)$ & $46(46.9 \%)$ & \multirow{2}{*}{$\mathrm{P}=0.04$} \\
\hline & No & $53(68.0 \%)$ & $52(53.1 \%)$ & \\
\hline \multirow{2}{*}{ Diarrhoea } & Yes & $43(55.0 \%)$ & $60(61.2 \%)$ & \multirow{2}{*}{$\mathrm{P}=0.50$} \\
\hline & No & $35(45.0 \%)$ & $58(59.2 \%)$ & \\
\hline \multirow{2}{*}{$\begin{array}{l}\text { Duration of symptoms } \\
\text { (months) }\end{array}$} & $\leq 6$ & $55(70.0 \%)$ & $79(80.6 \%)$ & \multirow{2}{*}{$\mathrm{P}=0.10$} \\
\hline & $>6$ & $23(30.0 \%)$ & $19(19.4 \%)$ & \\
\hline \multirow{2}{*}{ Iron Deficiency anemia } & Yes & $10(13.0 \%)$ & $36(36.7 \%)$ & \multirow{2}{*}{$\mathrm{P}<0.001$} \\
\hline & No & $68(87.0 \%)$ & $62(63.3 \%)$ & \\
\hline \multirow{2}{*}{ Hemoglobin(gm/dl) } & $\leq 10$ & $21(27.0 \%)$ & $50(51.0 \%)$ & \multirow{2}{*}{$P=0.001$} \\
\hline & $>10$ & $57(73.0 \%)$ & $48(49.0 \%)$ & \\
\hline \multirow{2}{*}{ Platelet count(lakh/cumm) } & $\leq 4.5$ & $68(87.0 \%)$ & $76(77.6 \%)$ & \multirow{2}{*}{$\mathrm{P}=0.12$} \\
\hline & $>4.5$ & $10(13.0 \%)$ & $22(22.6 \%)$ & \\
\hline \multirow{2}{*}{ Serum B12(pg/ml) } & $\leq 200$ & $20(25.0 \%)$ & $20(20.4 \%)$ & \multirow{2}{*}{$\mathrm{P}=0.50$} \\
\hline & $>200$ & $58(75.0 \%)$ & $78(79.6 \%)$ & \\
\hline \multirow{2}{*}{$\begin{array}{l}\text { Serum Calcium } \\
\text { (mg\%) }\end{array}$} & $\leq 8$ & $5(6.0 \%)$ & $15(15.3 \%)$ & \multirow{2}{*}{$\mathrm{P}=0.04$} \\
\hline & $>8$ & $73(36.0 \%)$ & $83(84.7 \%)$ & \\
\hline \multirow{2}{*}{$\begin{array}{l}\text { Serum Albumin } \\
\text { (gm\%) }\end{array}$} & $\leq 3$ & $2(36.0 \%)$ & 7(7.1\%) & \multirow{2}{*}{$\mathrm{P}=0.21$} \\
\hline & $>3$ & $76(64.0 \%)$ & $91(92.9 \%)$ & \\
\hline \multirow{2}{*}{ Bone pains } & Yes & $5(7.0 \%)$ & $30(30.6 \%)$ & \multirow{2}{*}{$P=0.001$} \\
\hline & No & $73(93.0 \%)$ & $68(69.4 \%)$ & \\
\hline \multirow{2}{*}{$\begin{array}{l}\text { Hepatic involvement (ALT } \\
\text { levels more than } 40 \mathrm{mu} / \mathrm{ml} \text { ) }\end{array}$} & Yes & 7 (9.0\%) & $39(39.8 \%)$ & \multirow{2}{*}{$\mathrm{P}=0.001$} \\
\hline & No & $71(91.0 \%)$ & $59(60.2 \%)$ & \\
\hline
\end{tabular}

Data: Number (Percentage \%) ,BMI- Body mass index, ALT - Alanine aminotransferase levels, P=Probability value

were $3.40(1.62-7.13)$ and $4.34(1.78-10.6)$ respectively [3]. Based on this evidence and decision analytic modeling data that suggest cost effectiveness, the Task Force recommends routine serologic screening for coeliac sprue in patients with IBS-D or IBS-M but in resourse constrained countries like India it is not cost effective to screen all IBS-D patients for CD [6]. In our study multivariate analysis showed that out of all variables duration of symptoms more than 6 months, IDA, Hb less than $10 \mathrm{mg} / \mathrm{dl}$, bone pains and ALT more than $40 \mathrm{mu} / \mathrm{ml}$ are the most important predictors of CD. In our study CD group had lower serum calcium levels and IDA but serum B12 levels were not significantly different in both groups which is explained by the pathophysiology of CD where there is more proximal bowel malabsorption. Previous studies have shown that $\mathrm{CD}$ predisposes a patient to low bone mineral density (BMD) at all sites of the skeleton and $26 \%-72 \%$ of patients with CD have osteoporosis or Osteopenia leading to bone pains [10-12]. Osteopenia develops as a result of impaired calcium absorption which is secondary to defective calcium transport by the diseased small intestine [12].While iron deficiency is the commonest cause of anaemia because of iron absorption from proximal small intestine, untreated subjects with $C D$ can have folic acid and less commonly vitamin B12 deficiency [9]. Elevated liver biochemical test levels in CD occur due to Autoimmune hepatitis or Lymphocytic hepatitis The liver is reported to be affected in 15\%-61\% of patients with CD, usually manifesting as an asymptomatic increase in serum transaminases, which normalizes in most of the patients $(80 \%)$ on GFD $[13,14]$. Presence of any of these variables justifies the screening for $\mathrm{CD}$ in patient presenting with small bowel diarrhoea especially in resourse constrained countries like India where it is not cost effective to screen all the patients with IBS-D for coeliac disease. In conclusion all patients with chronic diarrhoea, who have one or more of the following features like duration of symptoms for more than 6 months, IDA, Hb less than $10 \mathrm{gm} / \mathrm{dl}$, bone pains and ALT more than $40 \mathrm{mu} / \mathrm{ml}$, should be screened for CD.

\section{References}

1. Lovell RM, Ford AC. Global prevalence of and risk factors for irritable bowel syndrome: a meta-analysis. Clin Gastroenterol Hepatol. 2012;10(7);712-721. e4.doi: 10.1016/j.cgh.2012.02.029. Epub 2012 Mar 15.

2. American College of Gastroenterology Functional Gastrointestinal 
Disorders Task Froce. Evidence-based position statement on the management of irritable bowel syndrome in North America. Am J Gastroenterol. 2002;97(11 Suppl) :S1-5.

3. Ford AC, Chey WD, Talley NJ, Malhotra A, Spiegel BM, Moayyedi P. Yield of diagnostic tests for coeliac disease in individuals with symptoms suggestive of irritable bowel syndrome: systematic review and metaanalysis. Arch Intern Med. 2009;169(7):651-658. doi: 10.1001/ archinternmed.2009.22.

4. Wahnschaffe U, Schulzke JD, Zeitz M, Ullrich R. Predictors of clinicalresponse to gluten-free diet in patients diagnosed with diarrhea-predominant irritable bowel syndrome. Clin Gastroenterol Hepatol. 2007;5(7):844-850. quiz 769. Epub 2007 Jun 5.

5. Vazquez-Roque MI, Camilleri M, Smyrk T, Murray JA, Marietta E, O'Neill J, et al. A controlled trial of gluten-free diet in patients with irritable bowel syndrome-diarrhea: effects on bowel frequency and intestinal function. Gastroenterology. 2013;144(5):903-11. e3. doi 10.1053/j.gastro.2013.01.049. Epub 2013 Jan 25.

6. Coburn JA, Vande Voort JL, Lahr BD, Van Dyke CT, Kroning CM, Wu TT, et al. Human leukocyte antigen genetics and clinical features of self-treated patients on a gluten-free diet. $J$ Clin Gastroenterol 2013;47(10):828-833.doi: 10.1097/MCG.0b013e31828f531c.

7. Rubio-Tapia A, Hill ID, Kelly CP, Calderwood AH, Murray JA; American College of Gastroenterology. ACG clinical guidelines: diagnosis and management of coeliac disease. Am J Gastroenterol. 2013;108(5):656 676. quiz 677. doi: 10.1038/ajg.2013.79. Epub 2013 Apr 23.

8. Functional bowel disorders. In: Drossman DA, editor. Rome III: The functional gastrointestinal disorders. 3rd ed. McLean, Va.: Dagnon Associates; 2006.p 491

9. Kemppainen $\mathrm{T}^{1}$, Kröger $\mathrm{H}$, Janatuinen E, Arnala I, Kosma VM Pikkarainen $\mathrm{P}$, et al. Osteoporosis in adult patients with coeliac disease. Bone. 1999;24(3):249-255.

10. Bai JC, Gonzalez D, Mautalen C, Mazure R, Pedreira S, Vazquez $\mathrm{H}$, et al. Long-term effect of gluten restriction on bone mineral density of patients with coeliac disease. Aliment Pharmacol Ther. 1997;11(1):157-164

11.van der Windt DA, Jellema P, Mulder CJ, Kneepkens CM, van der
Horst HE. Diagnostic testing for coeliac disease among patients with abdominal symptoms: a systematic review.JAMA. 2010;303(17):1738146. doi: 10.1001/jama.2010.549.

12. Duggan JM, Duggan AE. Systematic review: the liver in coeliac disease. Aliment Pharmacol Ther. 2005;21(5):515-518.

13. Bardella MT, Fraquelli M, Quatrini M, Molteni N, Bianchi P, Conte D. Prevalence of hypertransaminasemia in adult coeliac patients and effect of gluten-free diet. Hepatology. 1995;22(3):833-836.

14. Caprai $S^{1}$, Vajro P, Ventura A, Sciveres M, Maggiore G, SIGENP Study Group for Autoimmune Liver Disorders in Celiac Disease. Autoimmune liver disease associated with coeliac disease in childhood: a multicenter study. Clin Gastroenterol Hepatol. 2008;6(7):803-806. doi: 10.1016/j.cgh.2007.12.002. Epub 2008 Feb 7.

15. Oxentenko AS, Murray JA. Coeliac Disease: Ten Things That Every Gastroenterologist Should Know. Clin Gastroenterol Hepatol. 2015;13:1396-404.

16. Yadav P, Das P, Mirdha BR, Gupta SD, Bhatnagar S, Pandey RM, et al. Currentspectrum of malabsorption syndrome in adults in India.Indian J Gastroenterol. 2011;30(1):22-28. doi: 10.1007/s12664-011-0081-0. Epub 2011 Mar 3.

17. Sharma M, Singh P, Agnihotri A, Das P, Mishra A, Verma AK, et al. Coeliac disease: a disease with varied manifestations in adults and adolescents. J Dig Dis. 2013;14(10):518-525. doi: 10.1111/17512980.12078.

18. Ford AC, Chey WD, Talley NJ, Malhotra A, Spiegel BM, Moayyedi P. Yield of diagnostic tests for coeliac disease in individuals with symptoms suggestive of irritable bowel syndrome:systematic review and metaanalysis. Arch Intern Med. 2009;169(7):651-658. doi: 10.1001/ archinternmed.2009.22.

19. Sainsbury A, Sanders DS, Ford AC. Prevalence of irritable bowel syndrome-type symptoms in patients with coeliac disease: a metaanalysis. Clin Gastroenterol Hepatol. 2013;11(4):359-365. e1. doi: 10.1016/j.cgh.2012.11.033. Epub 2012 Dec 13.

20.Aziz I, Sanders DS. The irritable bowel syndrome-coeliac disease connection. Gastrointest Endosc Clin N Am. 2012;22(4):623-637. doi: 10.1016/j.giec.2012.07.009. 